\title{
SPATIAL DISTRIBUTION OF GLACIER MELT DEDUCED FROM SOLAR RADIATION MAPPING WITH REFINED ATMOSPHERIC PARAMETERS
}

\author{
Tong LIU ${ }^{1}$, Tsuyoshi KINOUCHI ${ }^{2}$, and Fabiola LEDEZMA ${ }^{3}$ \\ 1 Student Member of JSCE, M.Sc., Interdisciplinary Graduate School of Science and Engineering, \\ Tokyo Institute of Technology (4259 Nagatsuta, Midori, Yokohama, Japan), \\ 2 Member of JSCE, Ph.D. Eng., Associate Professor, Interdisciplinary Graduate School of Science and Engineering, \\ Tokyo Institute of Technology (4259 Nagatsuta, Midori, Yokohama, Japan), \\ 3 Non-Member, M.Eng., Universidad Mayor de San Andrés (Calle 30, Cota Cota, CP 699, La Paz, Bolivia).
}

\begin{abstract}
Tropical glacier Huayna Potosi located in Cordillera Real in Bolivia was the main object in this paper. This study obtained two main parameters related to atmospheric conditions, i.e. diffuse fraction and atmospheric transmissivity, to evaluate the solar radiation distribution for the study of tropical glacier melts. The parameters were calculated by physically-based solar radiation formulas and then refined with observed data at ground level. These deduced parameters were conversely applied as input to GIS solar radiation model to obtain monthly spatial distributions of solar radiation considering atmospheric conditions and topographic from June 2011 to May 2012. Spatial distribution of glacier melt was finally simulated by applying glacier melt model considering air temperature and solar radiation.
\end{abstract}

Key Words : Solar radiation, topography, atmospheric transmissivity, diffuse fraction, glacier melt.

\section{INTRODUCTION}

The Huayna Potosi glacier $\left(16.26^{\circ} \mathrm{S}, 18.15^{\circ} \mathrm{W}\right.$, 6088 m.a.s.l.) in Andean region studied in this paper is part of the major water-supply resources for two cities in Bolivia, La Paz and El Alto. If glacier retreat is very rapid and proper countermeasures are not taken, water shortages may affect the drinking water-supply and irrigation of millions of local residents. Thus as climate changes, monitoring and estimating glacier melt in this region is essential for future fresh water availability.

Glacier melt is determined by the energy balance at the glacier surface, which is fundamentally controlled by the physical properties of glacier and the surrounding meteorological conditions. However, glaciers are normally not easy to access or monitor which lead to insufficient on-site measurements. As a result, plenty of ice- and snowmelt algorithms have been developed requiring only minimal meteorological data input, which rely on air temperature data to define the surface energy balance, sometimes with precipitation to define cloudiness ${ }^{1)}$. Detailed algorithms required solar radiation, air temperature, relative humidity, wind speed, and cloud cover data ${ }^{1}$. Considering the data availability, air temperature-index ice- and snowmelt algorithm including solar radiation was selected in this study ${ }^{2}$.

Air temperature can be calibrated with elevation while solar radiation is affected by both topography and air conditions. Previous ice- and snowmelt studies already included effects from topography by calculating potential direct solar radiation under clear sky condition, while air conditions were rarely verified ${ }^{2,3)}$. In the studies of solar radiation, air conditions including clearness, diffuse fraction, and atmospheric transmissivity, were given by either statistical correlations ${ }^{4,5)}$, or introducing correctors compared to observed data ${ }^{6}$.

In this paper, the main purpose is twofold. First, physically-based solar radiation formulations were applied with on-site meteorological data to obtain air conditions which were later conversely utilized as input parameters into the GIS to obtain spatial distribution of solar radiation considering both 

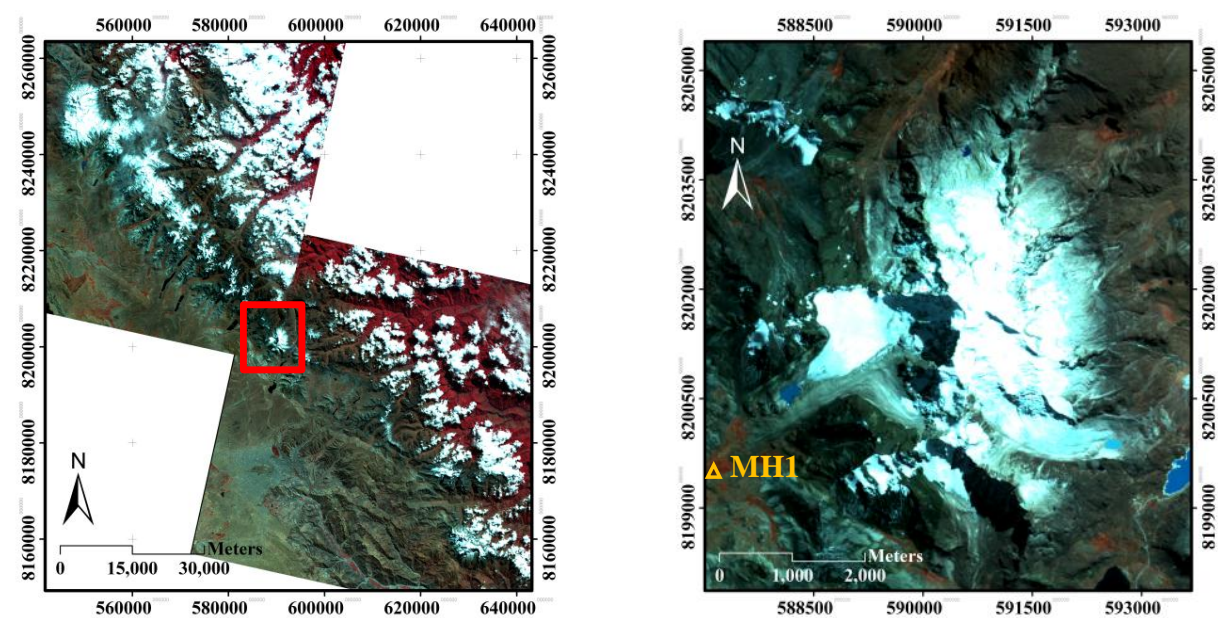

Fig.1 (Left) Overview of glaciers in the Cordillera Real in Bolivia (ALOS image with RGB = bands 4, 3, and 2; July 26, 2008). The studied area is shown in the red square. (Right) Enlarged study area. Yellow triangle presents meteorological station MH1 near Huayna Potosi glacier.

topographic and atmospheric effects. Secondly, spatial distribution of potential glacier melt was then estimated by applying the air temperature-index iceand snowmelt algorithm considering solar radiation.

\section{STUDY AREA}

The study area, Huayna Potosi glacier, locates in the Southern part of Cordillera Real, Bolivia (180 $\mathrm{km}$ extending in a northwest to southeast direction, centered at $16.22^{\circ} \mathrm{S}, 68.20^{\circ} \mathrm{W}$, flanked by the wet Amazon basin to the east and the dry Altiplano to the west) (Fig.1 left).

The climate of the region is controlled by seasonal oscillation of the Intertropical Convergence Zone (ITCZ). In the austral winter (April to September), the ITCZ is north of Bolivia and tropical anticyclones produce cold, dry conditions. In the austral summer (December to March), conditions are wet and warm as a result of the eastern intertropical flux that brings water vapor from the Atlantic Ocean ${ }^{7}$. The intertropical zone is further distinguished into two regions: the inner tropics with almost no seasonality in precipitation and the outer tropics with strong seasonality in precipitation. The meteorological differences have greatly influenced glacier mass balance. In the inner tropics, both accumulation and ablation occur throughout the year. The study region Cordillera Real is located in the outer tropics, where accumulation and ice/snow melt occur mainly during wet seasons. During dry seasons, ice/snow melt reduces and ice/snow sublimation increases ${ }^{899)}$.

\section{DATA}

Terrains of the study area were identified and generated using ASTER 30-m Global DEM data, which was distributed by the Land Processes Distributed Active Archive Center at USGS/EROS.

On-site observed data including air temperature, solar radiation, precipitation, wind velocity, and relative humidity was from the meteorological station NH1 near Huayna Potosi glacier from June 2011 to May 2012 (Fig.1 right and Fig.2).

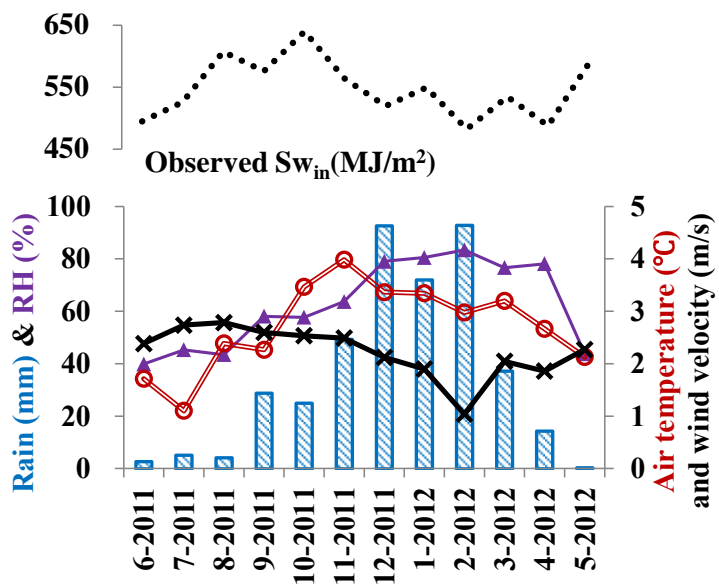

Fig.2 Meteorological conditions observed from June 2011 to May 2012 in station MH1

\section{METHODOLOGY}

Incoming solar radiation is affected by terrains and cloudiness as well as location and season. Terrain attributes, including elevation, slope, and slope orientation (also known as aspect or surface azimuth) can create strong local gradients in solar radiation. A model created by Fu and Rich in 2002 named as "The Solar Analyst" implemented on Geographic Information System (GIS) platform to calculate solar radiation based on DEM data ${ }^{10)}$. The model was superior to previously developed models mainly in two aspects: (1) it calculated incoming solar radiation with physically-based solar radiation 
formulations as a sum of direct and diffuse radiation; (2) despite of surface elevation, slope and aspect, shadows casted by surrounding topography were considered by generating upward-looking hemispherical viewshed (fisheye). However, the model used approximate value for atmospheric conditions, i.e. diffuse fraction and atmospheric transmissivity. In our study region, the difference shown in Fig.3(a) between observed and GIS deduced solar radiation was due to the ignorance of various atmospheric conditions. Therefore, these parameters need to be refined with observed data. In order to obtain the solar radiation under ideal clear sky condition in the study region, maximum value observed at each moment within a day during March 2012 was selected as the benchmark of the ideal clear day in the study region [Fig.3(b)]. The pattern of the solar radiation change under ideal clear sky within a day was basically identical as GIS deduced thus the algorithms applied in GIS were also applicable to our study region. [Fig.3(b)]

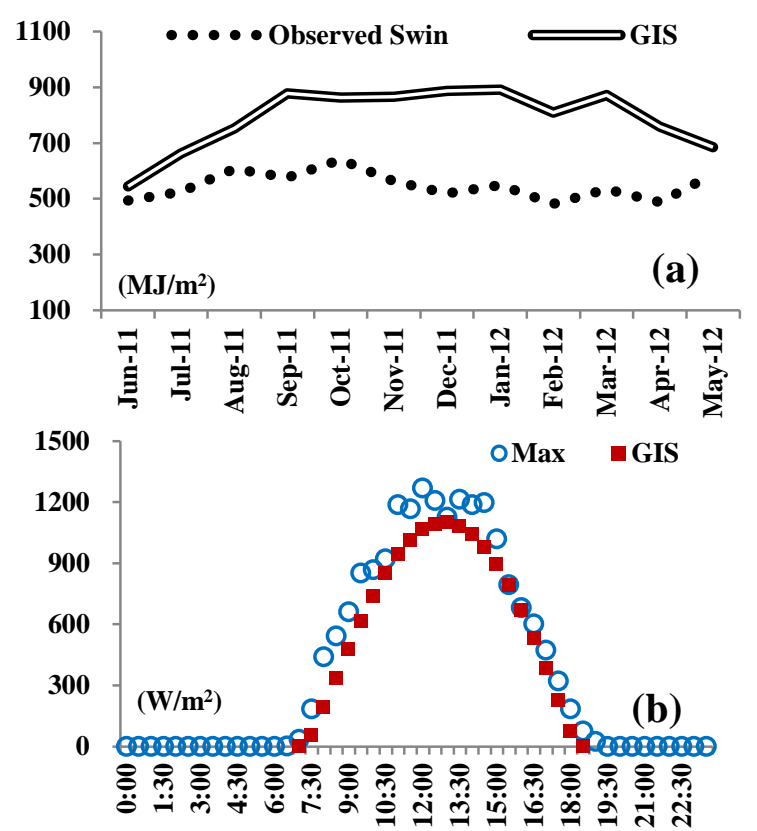

Fig.3 Comparison of solar radiation between observed and GIS deduced on (a) monthly solar radiation, and (b) maximum value observed at each moment within a day during March 2012 was selected as ideal clear day condition.

In the GIS, solar radiation is simulated as the sum of all sun map and sky map sectors ${ }^{10)}$. In this study, solar radiation was calculated without reference to the difference among sectors of sun and sky map in order to simplify the calculation.

Solar radiation $\left(S w_{i n}\right)$ is calculated as the sum of direct $\left(D i r_{\text {Total }}\right)$ and diffuse $\left(D i f_{\text {Total }}\right)$ radiation [Eq.(1)].

$$
S w_{\text {in }}=D i r_{\text {Total }}+D i f_{\text {Total }}
$$

\section{(1) Direct incident radiation}

The direct radiation ( $D i r_{\text {Total }}$ ) is calculated using the following equation ${ }^{10)}$ :

$$
\begin{gathered}
D i r_{\text {Total }}=S U N \cdot \beta^{m(\theta)} \cdot \text { Dur } \cdot \cos i \\
S U N=S U N^{*} / D^{2} \\
m(\theta)=e^{\left(-1.18 \times 10^{-4} \cdot H-1.638 \times 10^{-9} \cdot H^{2}\right)} / \cos \theta \\
\cos i=\cos \theta \cdot \cos S+\sin \theta \cdot \sin S \cdot \cos (\alpha-A)
\end{gathered}
$$

The solar constant, $S U N\left[\mathrm{~W} / \mathrm{m}^{2}\right]$, is solar flux outside the atmosphere at the certain Earth-Sun distance which was calibrated on daily basis by applying Eq.(3) $)^{6}$. SUN* is the average solar constant, $1367 \mathrm{~W} / \mathrm{m}^{2} . D$ is the Earth-Sun distance on certain day-of-year measured in Astronomical Unit (AU). $\beta$ is the atmospheric transmissivity in the direction of the solar zenith. $m(\theta)$ is the relative optical path length determined by the solar zenith angle $(\theta)$ and elevation $(H)$ [Eq.(4) ${ }^{10)}$. Dur is the time period applied in the analysis. $\cos i$ is the cosine value angle of incidence, which indicates the angle between the sun's rays irradiated on a surface and the axis normal to the surface [Eq.(5)] ${ }^{10)} . S$ and $A$ are surface zenith and azimuth angles, respectively. $\alpha$ is solar azimuth angle.

\section{(2) Diffuse solar radiation}

The diffuse radiation ( $D i f_{\text {Total }}$ ) is calculated, at each time interval, and corrected by the angle of incidence using the following equation ${ }^{10)}$ :

$$
\text { Dif } \text { Total }_{\text {Tif }}=R \cdot P_{\text {dif }} \cdot \text { Dur } \cdot \cos i
$$

where $R$ is the global normal radiation that is calculated with the following equation ${ }^{10)}$ :

$$
R=S U N \cdot \beta^{m(\theta)} /\left(1-P_{d i f}\right)
$$

where $P_{d i f}$, diffuse fraction, is the proportion of global normal radiation flux that is diffused.

\section{(3) Solar radiation}

As the sum of direct and diffuse radiation, solar radiation can be synthesized as Eq.(8) from all the previously described parameters and Eqs.(1) to (7).

$$
S w_{\text {in }}=S U N \cdot \beta^{m(\theta)} \cdot \operatorname{Dur} \cdot \cos i /\left(1-P_{d i f}\right)
$$

This equation demonstrated the three major aspects that determine the actual solar radiation received on the surface, i.e., the Sun, topography, and atmospheric properties. It's a relief that topographic information can be obtained from DEM, while atmospheric properties have always been the difficulty in such studies ${ }^{4), 5), 6)}$. In this study, related parameters and formulas were introduced to solve the problem.

\section{a) Air clearness}

A factor $\tau$ is introduced as air clearness factor 
[Eq.(9) $]^{11)}$.

$$
\tau=S w_{\text {in }}^{*} / E_{0}
$$

where $S w_{i n} *\left[\mathrm{~W} / \mathrm{m}^{2}\right]$ is the observed solar radiation and $E_{0} \quad\left[\mathrm{~W} / \mathrm{m}^{2}\right]$ is the exoatmospheric solar radiation calculated using Eq.(10) ${ }^{11)}$ :

$$
E_{0}=S U N\left(\sin \delta \sin \phi+0.9972 \cos \delta \cos \phi \cos \omega_{I}\right)
$$

where $\delta, \phi$, and $\omega_{I}$ are the declination, latitude and hour angle respectively at the middle of an hour.

\section{b) Diffuse fraction}

The default setting of diffuse fraction $\left(P_{d i f}\right)$ in GIS is 0.2 for very clear sky and 0.7 for very cloudy conditions $^{10)}$. In this study, instant air clearness factor $\tau$ enables immediate variations of the diffuse radiation with the observed data [Eq.(10) $]^{11)}$.

$$
P_{d i f}=0.384-0.416 \tau
$$

\section{c) Atmospheric transmissivity}

As demonstrated in previous sections, in Eq.(8), all the variables are already known or can be calculated at certain moment and location except for $\beta$. If all the information from a meteorological station is utilized, including topography and the observed solar radiation, the atmospheric transmissivity $\beta$ then is the only unknown variable left, which, as a result, is able to be accurately determined.

Atmospheric conditions, including atmospheric transmissivity $(\beta)$, air clearness $(\tau)$, and diffuse fraction $\left(P_{d i f}\right)$, were generated by applying the Eqs. (8), (9), and (10), respectively, to the ideal clear day described in methodology section [Fig.4(a)] and observed solar radiation on March 21, 2012 [Fig.4 (b)].

As shown in Fig.4(a), under the clear sky condition, both air clearness $(\tau)$ and diffuse fraction $\left(P_{d i f}\right)$ remained steady during the daytime. On the other hand, atmospheric transmissivity $(\beta)$ behaved as arc with relatively high values at dawn and dusk, while low value at noon. The default setting of atmospheric transmissivity $(\beta)$ under clear sky condition in the GIS is 0.5 , which is close to the low point in the middle of the day in Fig.4(a), while

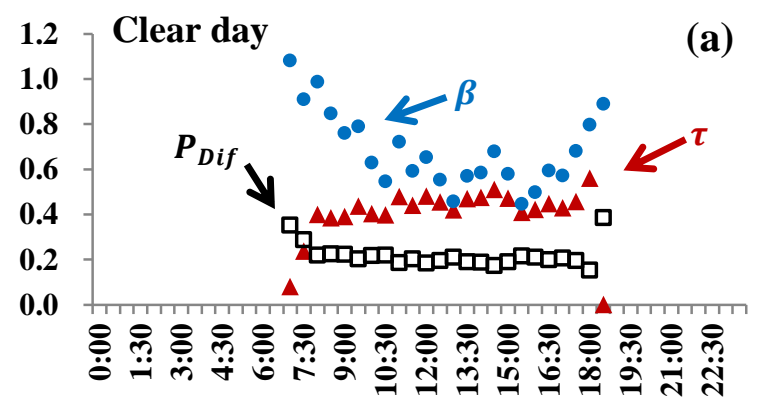

average value during daytime should be slightly higher.

Fig.4(b) showed the changing patterns of atmospheric conditions calculated with observed solar radiation on March 21, 2012. There were two sharp changes observed that all the variables varied simultaneously each time. Besides the variations, the main trend of each variable agreed with the patterns in Fig.4(a), which were with higher value at dawn and dusk, and the tendency of relative steady value close to noon.

Consequently, solar radiation was calculated with high frequency, i.e. hourly basis, which simulated the solar radiation with considering atmospheric conditions accurately $\left(\mathrm{R}^{2}=0.99\right)$. Daily or monthly average values may also be able to represent the atmospheric conditions in general, especially for long-term study or prediction. However, ignoring variations of air conditions within a day may lead to over- or underestimation.

\section{RESULTS AND DISCUSSION}

\section{(1) Distribution of solar radiation}

Topographic characteristics, including altitude, slope, and aspect, affect the glacier melt through their attributes to solar radiation. Fig.5 showed daily solar radiation in Huayna Potosi glacier calculated by GIS with inputting monthly average diffuse fraction $\left(P_{d i f}\right)$ and atmospheric transmissivity $(\beta)$ obtained from this study (Fig.6).

Fig.5(a) was calculated with data obtained in June 2011, and represented the daily solar radiation distribution around the June Solstice. Under actual sky conditions, June was one of the months in the year with lowest solar radiation (Fig.3(a)). Furthermore, June was also one of the most cloudless months with relatively low diffuse fraction $\left(P_{d i f}\right)$ and high atmospheric transmissivity $(\beta)$ (Fig.6). Since it represented a typical day during dry season there was less rainfall expected in dry season that accumulation could rarely happen. But air temperature was also relatively low at the same time that melt would not be the dominant process.

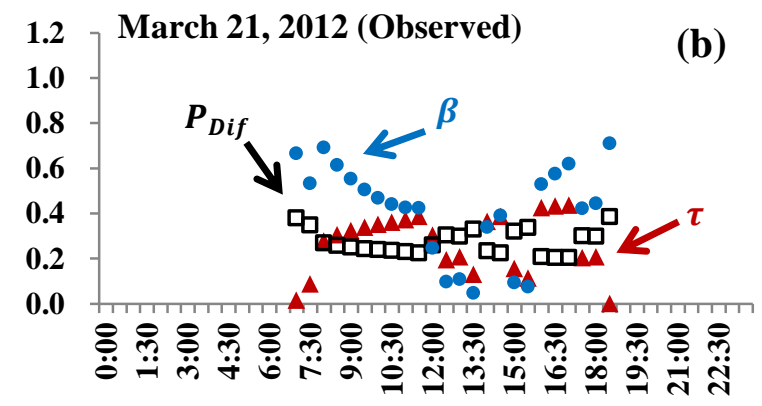

Fig.4 Diffuse fraction $\left(P_{d i f}\right)$, atmospheric transmissivity $(\beta)$ and air clearness $(\tau)$ variation within one day, respectively, which were deduced (a) from ideal clear day and (b) from observed data on March 21, 2012. 
Fig.5(b) and (d) representing the Equinoxes had similar patterns, which were calculated with data obtained in September 2011 and March 2012. However, solar radiation in September was much higher than that in March. As shown in Fig.6, September was with low diffuse fraction $\left(P_{d i f}\right)$ and high atmospheric transmissivity $(\beta)$ indicating clear sky conditions; as a result, more solar radiation was received. September was in the transition from dry season to wet season that both precipitation and relative humidity was low, while March was in the transition from wet to dry season that slightly high precipitation and relative humidity lead to cloudy sky conditions.

Fig.5(c) was calculated for December Solstice representing days in wet season with data obtained during December 2011, which had a unique pattern. During wet season, both precipitation and relative humidity was high that cloudy days were common; consequently, actual solar radiation glacier received was less than September although extraterrestrial solar radiation during December should be more intensive. The deduced relatively high diffuse fraction values and low atmospheric transmissivity values from field observation confirmed the effects from cloudiness in the wet season (from December
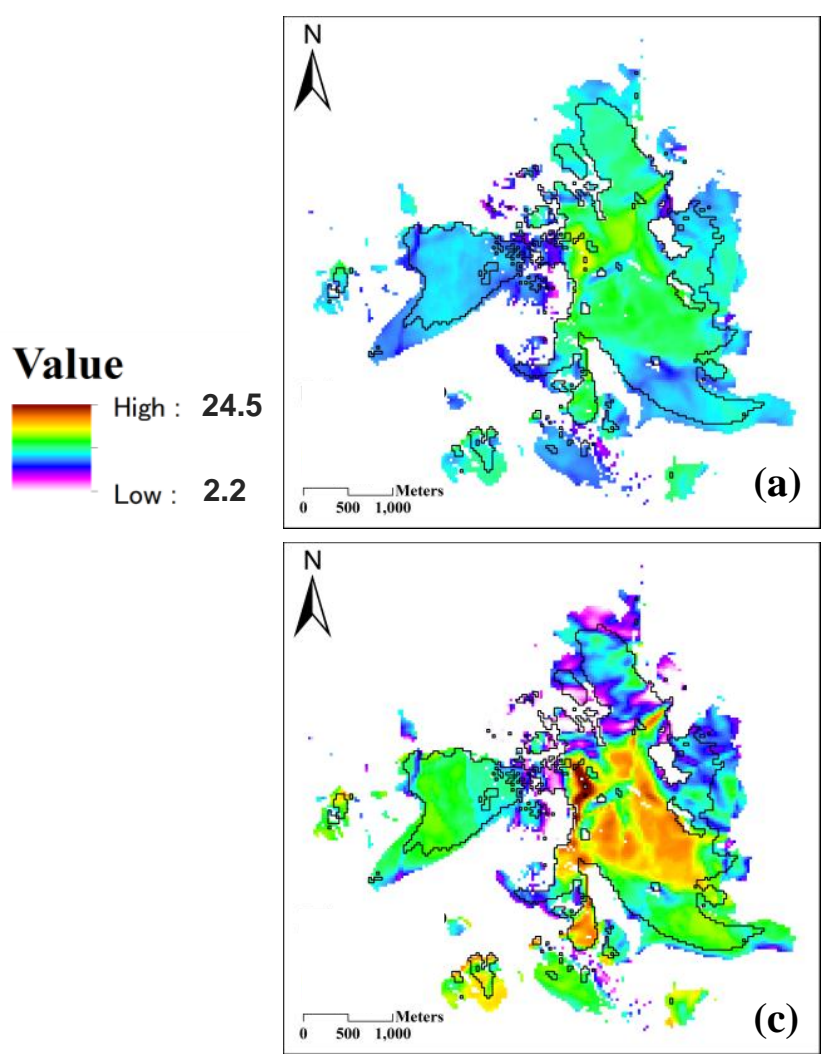

2011 to March 2012) (Fig.6). Meanwhile, air temperature reached the maximum during wet season that glacier melt would be the dominant for glacier loss. However, at the meantime, $80 \%$ of annual rainfall was expected and wind velocity was the lowest of the year during wet season that accumulation could happen (Fig.2) simultaneously.

\section{(2) Distribution of glacier melt}

Monthly glacier melt was calculated from June 2011 to May 2012 with Eqs.(12) and (13) ${ }^{12)}$ :

$$
\begin{gathered}
M=\frac{1}{n} \cdot\left(M F+S R \cdot(1-\alpha) \cdot S w_{i n}\right) \cdot T_{i} \\
T_{i}=T_{o b}+r \cdot\left(z_{o b}-z_{i}\right)
\end{gathered}
$$

where $M$ is glacier melt [mm/hour]; $T_{i}$ is air temperature $\left[{ }^{\circ} \mathrm{C}\right]$ calibrated with its elevation $z_{i}$, elevation of meteorological station $z_{o b}$ and observed air temperature $T_{o b}$ [Eq.(13)]; $S w_{i n}$ is solar radiation $\left[\mathrm{W} / \mathrm{m}^{2}\right]$ calculated by GIS with refined monthly average diffuse fraction and atmospheric transmissivity (Fig.6); $M F$ is melting factor related to air temperature, and defined as $5 \mathrm{~mm} /{ }^{\circ} \mathrm{C}$ per day; SR is melting factor related to solar radiation, and defined as $0.34 \mathrm{~m}^{2} \mathrm{~mm} / \mathrm{W} /{ }^{\circ} \mathrm{C}$ per day; $\alpha$ is the albedo on the glacier surface, which is defined as $0.5^{12}$.
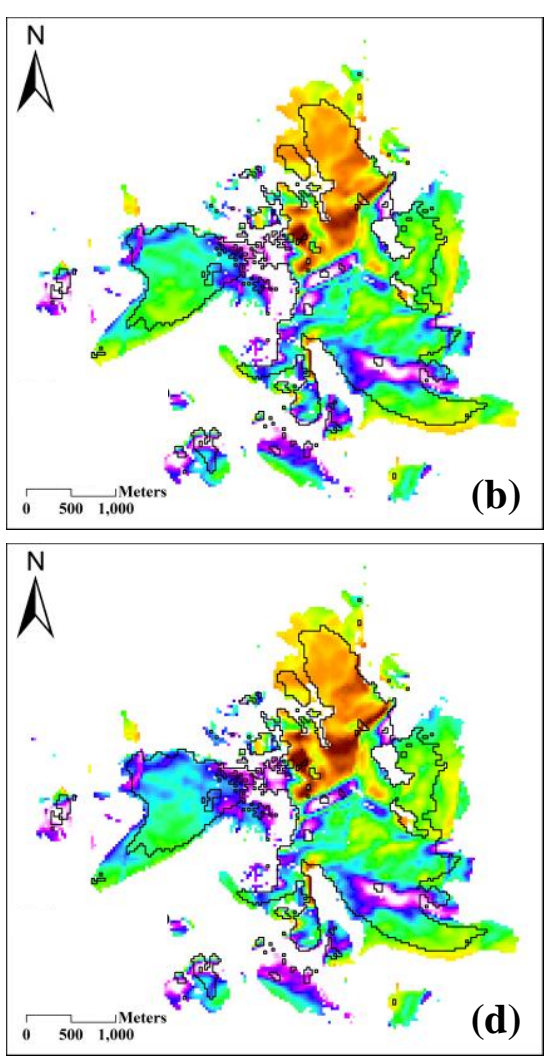

Fig.5 Daily solar radiation simulated by GIS with monthly average diffuse fraction $\left(P_{d i f}\right)$ and atmospheric transmissivity $(\beta)$ in Huayna Potosi glacier in (a) June 2011, representing the June Solstice, ranged from 2.4 to $3.8 \mathrm{MJ} / \mathrm{m}^{2}$;

(b) September 2011, representing the September Equinox, ranged from 9.2 to $23.8 \mathrm{MJ} / \mathrm{m}^{2}$;

(c) December 2011, representing the December Solstice, ranged from 5.5 to $11.9 \mathrm{MJ} / \mathrm{m}^{2}$;

and (d) March 2012, representing the March Equinox, ranged from 6.7 to $17.0 \mathrm{MJ} / \mathrm{m}^{2}$.

*The outer line of glacier indicated the area in 1987, while the inner line indicated the area in 2010. 


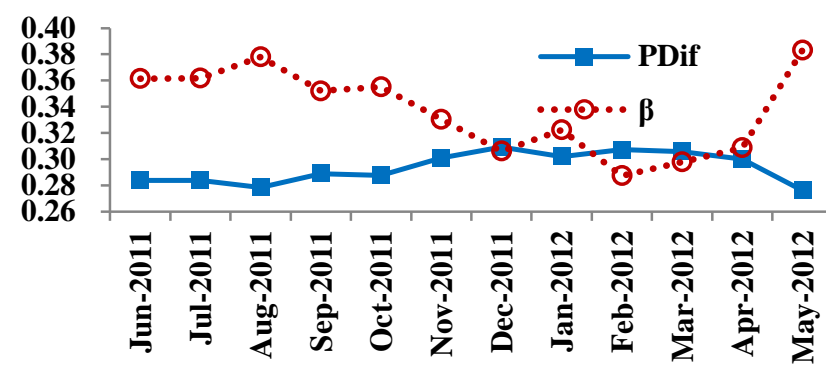

Fig.6 Monthly average diffuse fraction $\left(P_{d i f}\right)$ and atmospheric transmissivity $(\beta)$ from June 2011 to May 2012.

Potential glacier melt, which considered only solar radiation and air temperature, in December 2011 was calculated with uniform and distributed solar radiation (Fig.7). The results with uniform solar radiation presented much higher value as topographic effects were ignored. The effects from atmospheric conditions were already discussed and shown in Fig.3. Consequently, ignorance of either topographic shading effects or actual atmospheric conditions would lead to over-estimation of glacier melt. Furthermore, meteorological factors such as precipitation, wind speed, and relative humidity were not addressed in this study. Therefore, the potential glacier melt seems significant that possible accumulation, ablation, snowmelt, and refreezing process, was not concerned.

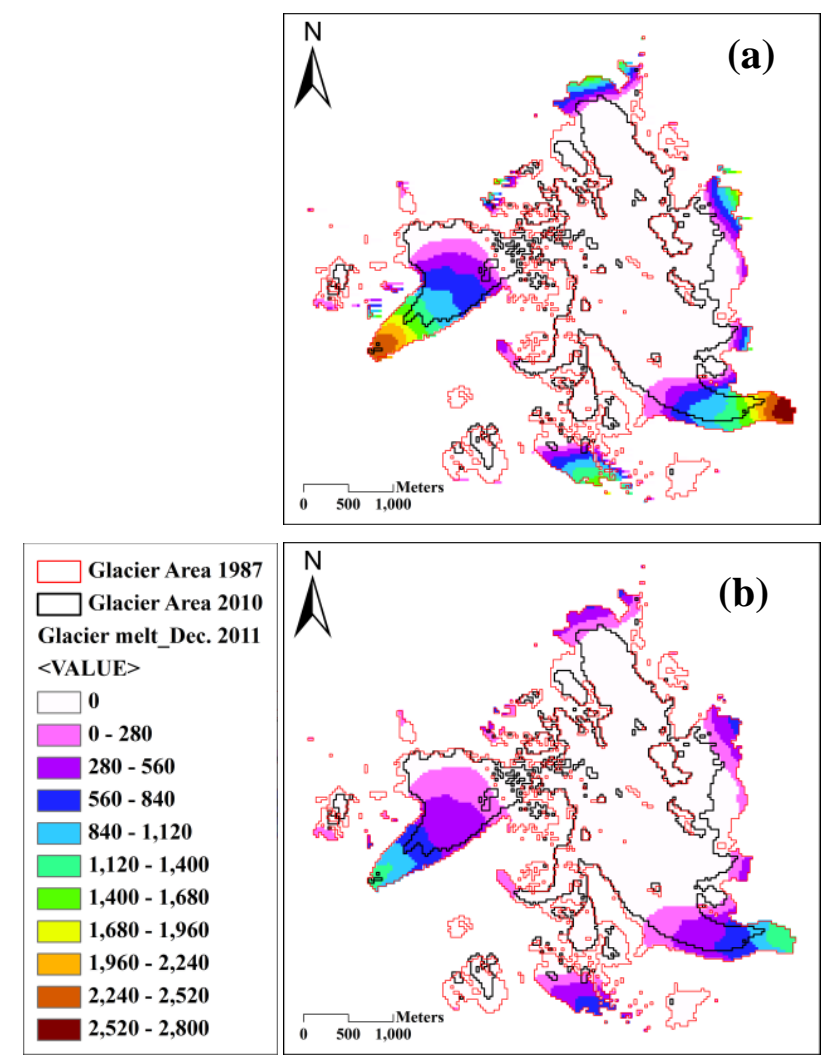

Fig.7 Potential glacier melt distribution in December $2011[\mathrm{~mm}$ per month] with (a) uniform (maximum glacier melt was $2700 \mathrm{~mm}$ ) and (b) distributed (maximum glacier melt was $1400 \mathrm{~mm}$ ) solar radiation.

\section{CONCLUSION}

This study mapped solar radiation considering atmospheric conditions and topographic effects. The atmospheric conditions, including diffuse fraction and atmospheric transmissivity, were obtained from physically-based formulations and refined with observed data. The parameters were utilized as input into the GIS to obtain spatial distribution of solar radiation considering topographic effects in order to calculate spatially distributed glacier melt. The methods were proved effective and applicable in tropical glaciers. Distributed solar radiation considering atmospheric conditions enables further accurate evaluation of accumulation, ablation, melt, and refreezing process over glaciers and snow.

ACKNOWLEDGMENT: The study was supported by JST/JICA, SATREPS (Science and Technology Research Partnership for Sustainable Development).

\section{REFERENCES}

1) Melloh, R. A.: A Synopsis and Comparison of Selected Snowmelt Algorithms", US Army Corps of Engineers, Cold Regions Research and Engineering Laboratory, CRREL Report, 99-8, 1999.

2) Hock, R.: A distributed temperature-index ice-and snowmelt model including potential direct solar radiation, Journal of Glaciology, 45 (149), 101-111, 1999.

3) Zhang, Y., Liu, S., Xu, J. and Shangguan, D.: Glacier change and glacier runoff variation in the Tuotuo River basin, the source region of Yangtze River in western China, Environmental Geology, Vol. 56, No. 1, 59-68, 2007.

4) Batlles, F. J., Bosch, J. L., Tovar-Pescador, J., MartínezDurbán, M., Ortega, R. and Miralles, I.: Determination of atmospheric parameters to estimate global radiation in areas of complex topography: Generation of global irradiation map, Energy Conversion and Management, 49(2), 336-345, 2008.

5) Baigorria, G. A., Villegas, E. B., Trebejo, I., Carlos, J. F. and Quiroz, R.: Atmospheric transmissivity: distribution and empirical estimation around the central Andes, International Journal of Climatology, Vol. 24, No. 9, 1121-1136, 2004.

6) Pons, $X$. and Ninyerola, M.: Mapping a topographic global solar radiation model implemented in a GIS and refined with ground data, International Journal of Climatology, Vol. 28, 1821-1834, 2008.

7) Ribstein, P., Tiriau, E., Francou, B. and Saravia, R.: Tropical climate and glacier hydrology: a case study in Bolivia, Journal of Hydrology, Vol. 165, 221-234, 1995.

8) Kaser, G.: Glacier-climate interaction at low latitudes, Journal of Glaciology, Vol. 47, No. 157, 195-204, 2001.

9) Favier, V., Wagnon, P. and Ribstein, P.: Glaciers of the outer and inner tropics: A different behaviour but a common response to climatic forcing, Geophysical Research Letters, Vol. 31, No. 16, 1-5, 2004.

10) Fu, P. and Rich, P.: The solar analyst 1.0 user manual, Helios Environmental Modeling Institute, 2000.

11) Wong, L. T. and Chow, W. K.: Solar radiation model, Applied Energy, Vol. 69, No. 3, 191-224, 2001.

12) Kinouchi, T., Ledezma, F., Liu, T. and Mendoza, J.: Impact of Glacier Disappearance on Runoff from a Glacierized Catchment in the Andes, Journal of Japan Society of Civil Engineers, Ser.B1(Hydraulic Engineering),2013 (Submitted).

(Received September 30, 2012) 